\title{
Prognostic factors for elderly patients with primary malignant bone and soft tissue tumors
}

\author{
TADASHI IWAI, MANABU HOSHI, JUN TAKADA, NAOTO OEBISU, \\ MASANARI AONO, MASATSUGU TAKAMI, MAKOTO IEGUCHI and HIROAKI NAKAMURA \\ Department of Orthopedic Surgery, Osaka City University Graduate School of Medicine, \\ Abeno-Ku, Osaka 545-8585, Japan
}

Received September 12, 2014; Accepted June 11, 2015

DOI: $10.3892 / \mathrm{ol} .2015 .3432$

\begin{abstract}
The number of patients with primary malignant bone and soft tissue tumors in Japan is increasing in line with the increasing size of the elderly population. The aim of the present study was to determine the prognostic factors of primary malignant bone or soft tissue tumors in elderly patients. Clinical data was obtained from 90 patients, aged $\geq 65$ years, with primary malignant bone or soft tissue tumors (bone, 20 cases; and soft tissue, 70 cases), treated at the Osaka City University Hospital between 1993 and 2013. Clinical information prior to treatment and tumor type, location, size, depth, grade and American Society of Anesthesiologists-Physical Status (ASA-PS) score were evaluated in order to identify prognostic factors using the Cox proportional hazards regression model. In addition, 5-year survival rates were evaluated using the Kaplan-Meier method. The average follow-up period was 44.8 months and the 5-year overall survival rate was $77.5 \%$. In the multivariate analysis, ASA-PS score and high-grade sarcoma were found to be associated with a poorer overall survival. No significant differences were observed between the patient group aged $65-74$ years and that aged $\geq 75$ years. In general, aging is associated with physically reduced function and an increased prevalence of comorbidities. It was therefore expected that increasing age may be a predictive factor for poor prognosis. However, the results of the present study suggested that ASA-PS score and tumor grade were significant factors associated with poor prognosis, whereas increasing age was not. Therefore, the treatment of elderly patients with primary bone and soft tissue tumors should not be based on age.
\end{abstract}

Correspondence to: Dr Tadashi Iwai, Department of Orthopedic Surgery, Osaka City University Graduate School of Medicine, 1-4-3 Asahi-Machi, Abeno-Ku, Osaka 545-8585, Japan

E-mail: qq329xpd@opal.ocn.ne.jp

Key words: elderly, bone and soft tissue tumor, American Society of Anesthesiologists-Physical Status, prognostic factor, tumor grade, surgery

\section{Introduction}

At present, in the Japanese population the proportion of elderly people is growing, while the birthrate is declining (1). The World Health Organization defines the elderly population as persons with a chronological age of $\geq 65$ years (2). The statistics indicate that the proportion of people aged $\geq 65$ years in the total Japanese population was $24.1 \%$ in 2010 (3). As recorded in the registry of the Musculoskeletal Tumor Committee of the Japanese Orthopedic Association, the incidence of malignant bone and soft tissue tumors is increasing (4). Aging itself is a strong predisposing factor for the development of numerous types of malignant tumors (5); in addition, the incidence of these tumors increases progressively with age (6).

Aging has been reported to be an indicator of poor prognosis in the treatment of bone and soft tissue tumors (6-8); in general, this was thought to be due to reduced physiologic function and a decreased general tolerance to cancer treatment in elderly patients. The majority of orthopedic oncologists are likely to select less invasive or conservative treatments for elderly patients, especially for those with poor performance status (8-13). However, due to recent developments in multimodal medical technologies, including diagnostic modalities, chemotherapy, anesthesia and surgical methods, more elderly patients may be able to undergo surgery with a reduced risk than has previously been the case (8-13). There have been few previous studies concerning elderly patients with primary malignant bone and soft tissue tumors (8-13). The aim of the present study was to retrospectively analyze the clinical outcomes of elderly patients diagnosed with these tumors and to determine any potential prognostic factors.

\section{Patients and methods}

Patients. Clinical data was obtained from 90 patients, aged $\geq 65$ years, with a diagnosis of primary malignant bone or soft tissue tumors (bone, 20 cases; and soft tissue, 70 cases), treated between March 1993 and May 2013 at the Department of Orthopedic Surgery, Osaka City University Hospital Affiliated to Osaka City University Garduate School of Medicine (Osaka, Japan). The data was not fully analyzed until the last follow-up appointment in September 2013. The study population consisted of 46 male and 44 female patients, 
with a mean age at diagnosis of $75.2 \pm 6.8$ years (range, 65-94 years). The median follow-up time in the present study was 44.8 months (range, 1-163 months). The present study was approved by the Institutional Review Board of Osaka City University Graduate School of Medicine. Written informed consent was obtained from all patients.

Patient diagnosis. On initial presentation to the Osaka City University Hospital, patients underwent radiological evaluated using plain radiographs, local computed tomography (CT) and magnetic resonance imaging (MRI) with or without gadolinium enhancement. Distant metastases to the lungs were also checked for using CT. Systemic metastases were screened using fluorodeoxyglucose-positron emission tomography (FDG-PET)/CT. Radiologically, if a malignant tumor was suspected it was recommended that the patient underwent a biopsy procedure. All biopsy specimens of resected tissues were diagnosed by a pathologist with specialized training and expertise in sarcoma pathology, using standard diagnostic criteria for bone and soft tissue sarcoma subtyping (14). The histological grade was determined according to the four grade system for bone tumors (15) and according to the Federation Nationale des Centres de Lutte Contres le Cancer grading system for soft tissue tumors (16). The grading system for bone tumors, with the exception of the Ewing sarcoma, was based on the technique described by Broders (15). Grade 1 and 2 tumors were considered as low grade, and grade 3 and 4 tumors as high grade. With regard to soft tissue tumors, Grade 1 tumors were classified as low grade, and grade 2 and 3 tumors were classified as high grade. The clinical staging of each patient was evaluated in accordance with the American Joint Committee on Cancer 7th edition for soft tissue tumors and bone cancer $(17,18)$.

Parameters. The following parameters were evaluated prior to treatment: Age, gender, tumor depth, tumor site, tumor size, tumor type (bone or soft tissue tumor), histological diagnosis, histological grade, preoperative physical status using the American Society of Anesthesiologists-Physical Status (ASA-PS) classification (19) and oncological outcome. Tumor size and location were estimated using MRI and/or CT, and size was classified as $<5 \mathrm{~cm}, 5-15 \mathrm{~cm}$ and $>15 \mathrm{~cm}$. The ASA-PS scores were assessed by anesthesiologists regarding the risks associated with surgery. Surgical margins of the resected specimens were evaluated according to the guidelines of the Japanese Orthopedic Association (20).

Patient follow-up. Following treatment, patients were generally followed up at regular intervals of 3 months, with local examination and chest radiographs or CT for the first 2 years post treatment. Between 3 and 5 years post treatment, patients were followed up every 6 months and yearly thereafter. MRI scans were also conducted in order to supplement local examination for the detection of local recurrence every 6 months for first 3 years following treatment. Patients treated more recently were followed up monthly, with physical examination for the first 3 months post treatment and the last patient to undergo treatment in May 2013 was followed up for 4 months. The follow-up time was defined as the interval from the definitive tumor treatment (surgery or radiotherapy) to the last follow-up.
Statistical analysis. Curves for the overall survival of patients with sarcoma following treatment were plotted using the Kaplan-Meier method (21). The log-rank test was used to compare overall survival between the subgroups of patients (22). The Cox proportional hazards regression model was used to assess the ability of the patient characteristics to predict overall survival (23). Univariate analysis was performed by means of the log-rank test. Multivariate analysis was performed using the Cox proportional hazards regression model, including only factors where $\mathrm{P}<0.1$ in the univariate analysis. In all analyses, $\mathrm{P}<0.05$ was considered to indicate a statistically significant difference between values. The SAS system (SAS 9.3; SAS Institute, Inc., Cary, NC, USA) was used throughout to perform the various analyses.

\section{Results}

Clinical information. Clinical information for the elderly patients is summarized in Table I. The median patient age at the time of the initial visit to the Department of Orthopedic Surgery, Osaka City University Hospital was 75.2 years (range, 65-94 years); the study population consisted of 46 male and 44 female patients. Concerning the evaluation of preoperative physical status, there were 21 patients who had associated comorbidities with an ASA-PS score of $\geq 3$; of note, cardiovascular comorbidities, including hypertension, ischemic heart disease, previous myocardial infarction and previous cerebrovascular accident, accounted for a number of the total documented conditions (19). The locations of bone tumors were as follows: Femur, $n=5$; pelvis, $n=5$; rib, $n=3$; sacrum, $\mathrm{n}=2$; humerus, $\mathrm{n}=2$; tibia, $\mathrm{n}=1$; and scapula, $\mathrm{n}=1$. The locations of soft tissue tumors were the lower limb in 38 patients, trunk in 19 patients and upper limbs in 13 patients.

Histological diagnosis. Histological diagnosis of the patients is summarized in Table II. Of the 20 bone sarcomas, 12 were chondrosarcomas, 4 were osteosarcomas, 3 were chordomas and 1 was a round cell sarcoma. Of the 70 soft tissue sarcomas, 39 were liposarcomas, 11 were leiomyosarcomas, 7 were myxofibrosarcomas, 6 were pleomorphic malignant fibrous histiocytomas, 2 were malignant peripheral nerve sheath tumors and there was 1 case each of fibrosarcoma, synovial sarcoma, malignant solitary fibrous tumor, plasmacytoma and epithelioid sarcoma.

Treatment of tumors. A total of 79 patients underwent surgical resection of their tumors; of which, the surgical margins were evaluated as being wide in 59 cases, marginal in 17 cases and intralesional in 3 cases. A further 11 patients did not receive surgery due to the location of their tumors, which made resection difficult; in these cases, preoperative evaluation indicated that they were in an unsuitable condition for surgery or the patient opted not to undergo surgery. A total of 5 patients received radiation therapy, of which 3 underwent heavy particle beam therapy. A total of 4 patients received chemotherapy and the best supportive care was selected for 2 patient. No patients underwent amputation or disarticulation.

Oncological outcome. All patients were followed up at the Department of Orthopedic Surgery, Osaka City 
Table I. Clinical information for the elderly patients.

\begin{tabular}{|c|c|}
\hline Factors & Number \\
\hline \multicolumn{2}{|l|}{ Age (years) } \\
\hline $65-74$ & 43 \\
\hline$\geq 75$ & 47 \\
\hline \multicolumn{2}{|l|}{ Gender } \\
\hline Male & 46 \\
\hline Female & 44 \\
\hline \multicolumn{2}{|l|}{ Anatomical site } \\
\hline Extremity & 59 \\
\hline Nonextremity & 31 \\
\hline \multicolumn{2}{|l|}{ Tumor depth } \\
\hline Deep & 81 \\
\hline Superficial & 9 \\
\hline \multicolumn{2}{|l|}{ Tumor size } \\
\hline $0-5 \mathrm{~cm}$ & 14 \\
\hline $5-15 \mathrm{~cm}$ & 65 \\
\hline$>15 \mathrm{~cm}$ & 11 \\
\hline \multicolumn{2}{|l|}{ Grade } \\
\hline Low & 27 \\
\hline High & 63 \\
\hline \multicolumn{2}{|l|}{ AJCC stage } \\
\hline \multicolumn{2}{|l|}{ Bone tumor } \\
\hline IA & 5 \\
\hline IB & 3 \\
\hline IIA & 6 \\
\hline IIB & 4 \\
\hline IVA & 2 \\
\hline \multicolumn{2}{|c|}{ Soft tissue tumor } \\
\hline I & 20 \\
\hline II & 19 \\
\hline III & 23 \\
\hline IV & 8 \\
\hline \multicolumn{2}{|l|}{ ASA-PS } \\
\hline 1 & 18 \\
\hline 2 & 51 \\
\hline 3 & 20 \\
\hline 4 & 1 \\
\hline
\end{tabular}

Median age, 75.2 years (range, 65-94 years). ASA-PS, American Society Of Anesthesiologists-Physical Status; AJCC, American Joint Committee On Cancer.

University Hospital. The average follow-up period was 44.8 months (range, 1-163 months). Regarding oncological outcome at the last follow-up, 52 patients were in a continuous disease-free condition, 8 demonstrated no evidence of disease, 13 were alive with disease, 15 succumbed to the disease and 2 mortalities occurred due to unassociated causes.

Prognostic factors. Univariate analysis revealed that ASA-PS was a statistically significant prognostic factor for
Table II. Histopathology.

\begin{tabular}{lr}
\hline Tumor type & Number \\
\hline Bone & 12 \\
Chondrosarcoma & 4 \\
Osteosarcoma & 3 \\
Chordoma & 1 \\
Round cell sarcoma & \\
Soft tissue & 39 \\
Liposarcoma & 11 \\
Liomyosarcoma & 7 \\
Myxofibrosarcoma & 6 \\
Plepmorphic malignant fibrous hystiocytoma & 2 \\
Malignant periperal nerve sheath tumor & 1 \\
Fibrosarcoma & 1 \\
Synovial sarcoma & 1 \\
Malignant solitary fibrous tumor & 1 \\
Soft tissue plasmacytoma & 1 \\
Epithelioid sarcoma & \\
\hline
\end{tabular}

the overall survival rate of patients $(\mathrm{P}=0.002)$ (Table III). In addition, using multivariate analysis, ASA-PS was identified as a significant prognostic factor $(\mathrm{P}=0.003)$, as was tumor grade $(\mathrm{P}=0.048)$ (Table IV).

Survival rates. The 5-year overall survival rate was calculated using the Kaplan-Meier survival curve to be $77.5 \%$ (Fig. 1). There was no significant difference in 5-year overall survival between patients aged 65-74-years and patients aged $\geq 75$ years $(\mathrm{P}=0.23)$ (Fig. 2). In addition, no significant difference was identified between tumor types (bone vs. soft tissue sarcoma; $\mathrm{P}=0.43)$; by contrast, a significant difference was observed for the ASA-PS score $(\mathrm{P}=0.001)$ (Fig. 3) and tumor grade $(\mathrm{P}=0.04)$ (Fig. 4). The 5-year overall survival rate for patients with an ASA-PS score of $\geq 3$ was decreased compared with that for patients with ASA-PSs score of 1 and 2 (45.5 vs. $79.7 \%$ ). Furthermore, the 5-year overall survival rate for patients with a high-grade tumor was reduced compared with that for patients with a low grade tumor (70.8 vs. $95.2 \%)$.

\section{Discussion}

In Japan, the number of elderly people in the population has been increasing; of note, it was reported by the Ministry of Health, Labour and Welfare of Japan that the average life span is 79.64 years for males and 86.39 years for females (3). Previously, various factors associated with aging, including decreased performance status and the presence of significant comorbidities, have caused surgeons and medical oncologists to be cautious of using aggressive treatments for elderly patients with malignant tumors. This is due to the belief that an aggressive approach may have greater negative effects on these patients compared with on younger patients (24). However, with the development of multidisciplinary modalities, there are increased possibilities for aggressively treating elderly patients (25). 
Table III. Cox proportional hazards univariate analysis of overall survival.

\begin{tabular}{lllll}
\hline Variable & Hazard for & Relative to & Hazard ratio (CI) & P-value \\
\hline Age & $\geq 75$ years & 65-74 years & $2.05(0.66-6.38)$ & 0.217 \\
Gender & Female & Male & $0.65(0.24-1.76)$ & 0.402 \\
Depth & Deep & Superficial & $1.75(0.28-13.3)$ & 0.592 \\
ASA-PS & $\geq 3$ & $1-2$ & $4.94(1.79-13.6)$ & 0.002 \\
Grade & High & Low/intermediate & $6.56(0.86-49.8)$ & 0.069
\end{tabular}

ASA-PS, American society of anesthesiologists-physical status; CI, confidence intervals.

Table IV. Cox proportional hazards multivariate analysis of overall survival.

\begin{tabular}{lllll}
\hline Variable & Hazard for & Relative to & Hazard ratio (CI) & P-value \\
\hline ASA-PS & $\geq 3$ & 1 and 2 & $5.77(1.81-18.4)$ & 0.003 \\
Grade & High & Low/intermediate & $7.82(1.02-60.2)$ & 0.048 \\
\hline
\end{tabular}

Adjusted for age, gender and depth. ASA-PS, American society of anesthesiologists-physical status; CI, confidence intervals.

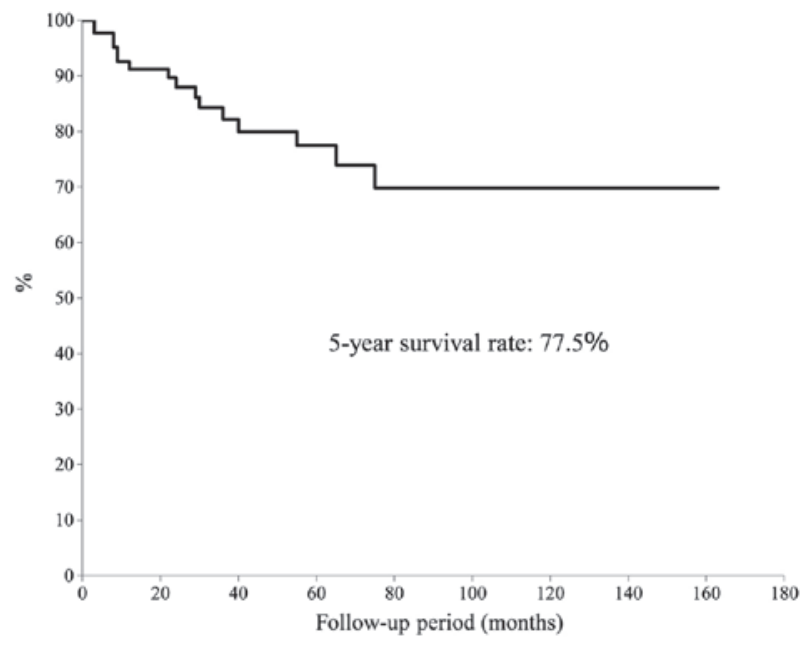

Figure 1. Overall survival rate of aged patients.

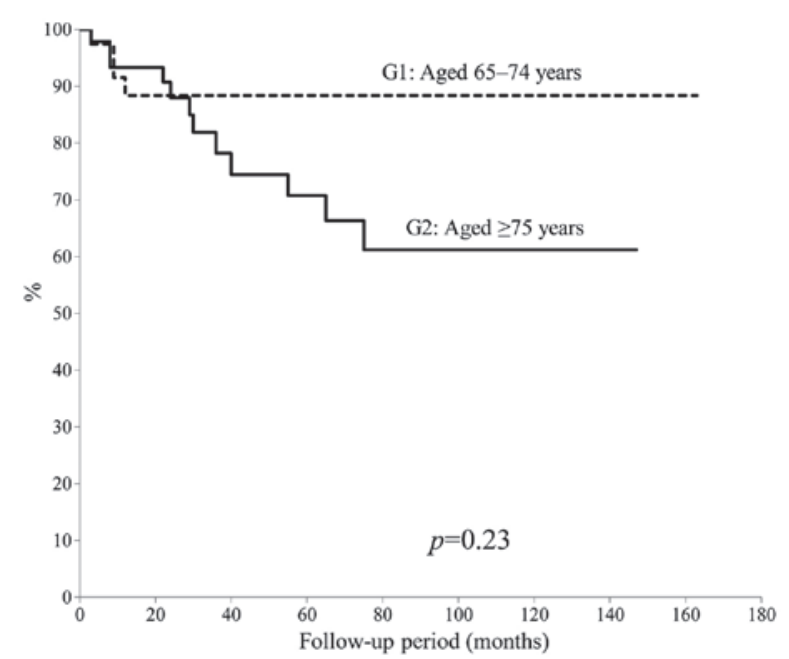

Figure 2. Survival rates of patients aged $65-74$ years and $\geq 75$ years.

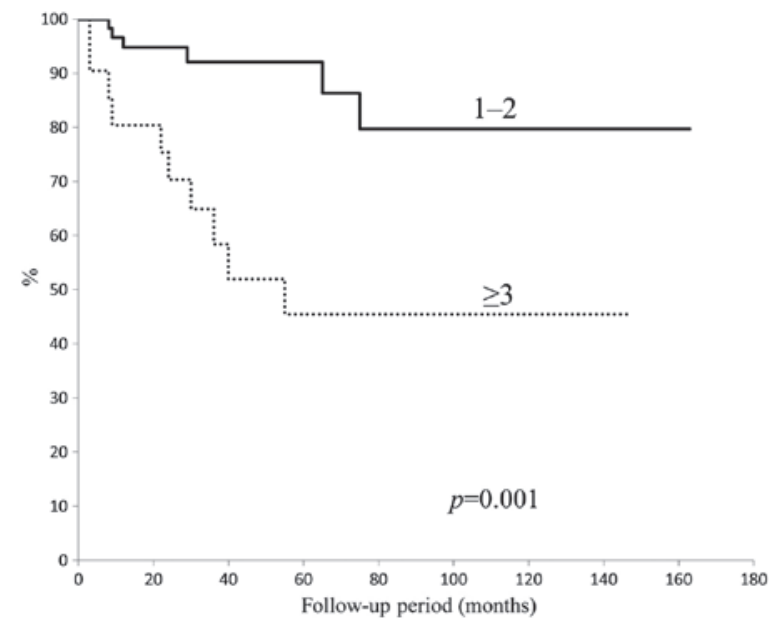

Figure 3. Survival rate of patients with different American Society of Anesthesiologists-Physical Status scores.

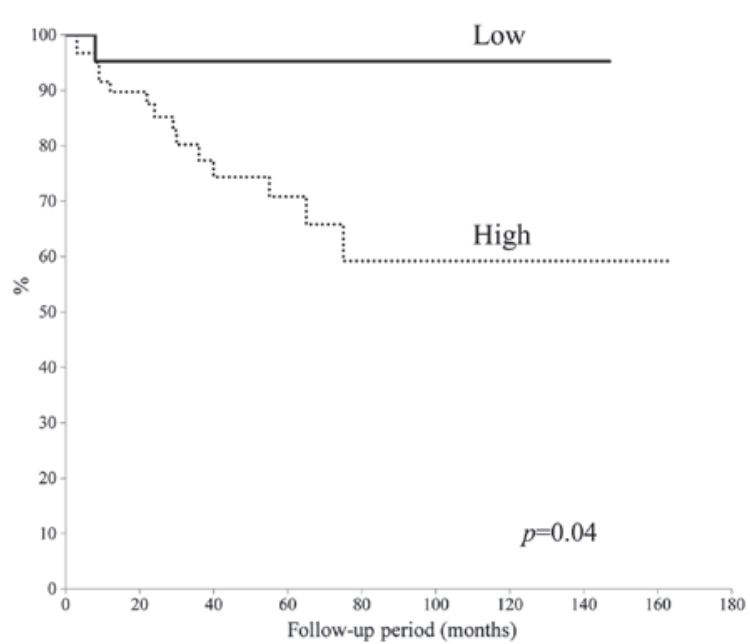

Figure 4. Survival rates of patients with high and low grade tumors. 
Table V. Previous studies concerning the treatment of elderly patients with bone and soft tissue tumors.

\begin{tabular}{|c|c|c|c|c|c|c|c|}
\hline Author & Year & $\begin{array}{l}\text { Age, } \\
\text { years }\end{array}$ & $\begin{array}{l}\text { No. of } \\
\text { patients }\end{array}$ & $\begin{array}{l}\text { Surgical } \\
\text { margins }\end{array}$ & $\begin{array}{l}\text { Prognostic } \\
\text { factors }\end{array}$ & $\begin{array}{l}5 \text {-year survival } \\
\text { rate }(\%)\end{array}$ & Ref \\
\hline Osaka et al & 2003 & $\geq 65$ & 25 & $\begin{array}{l}\text { Wide }(76 \%) \text {, marginal }(16 \%) \text {, } \\
\text { intralesional }(8 \%)\end{array}$ & Age, grade & 79.6 & 8 \\
\hline Boden et al & 2006 & $\geq 80$ & 50 & Clear margin $(76 \%)$ & Not identified & 46.0 & 10 \\
\hline Lahat et al & 2009 & $\geq 65$ & 295 & $\begin{array}{l}\text { Margin negative }(63.1 \%) \text {, } \\
\text { margin positive }(27.7 \%)\end{array}$ & $\begin{array}{l}\text { Age, tumor } \\
\text { size, grade }\end{array}$ & 63.0 & 9 \\
\hline Torigoe et al & 2010 & $\geq 70$ & 14 & $\begin{array}{l}\text { Wide and amputation }(85.7 \%) \text {, } \\
\text { marginal }(14.3 \%)\end{array}$ & $\begin{array}{l}\text { Bone tumor, } \\
\text { grade }\end{array}$ & 35.0 & 11 \\
\hline Kozawa et al & 2013 & $\geq 65$ & 78 & $\begin{array}{l}\text { Wide }(71.8 \%) \text {, marginal }(11.5 \%) \text {, } \\
\text { intralesional }(3.8 \%)\end{array}$ & Not identified & 72.0 & 12 \\
\hline Yoneda et al & 2013 & $\geq 70$ & 158 & $\begin{array}{l}\text { Adequate wide }(66.5 \%) \text {, } \\
\text { inadequate wide }(33.5 \%)\end{array}$ & $\begin{array}{l}\text { Male gender, } \\
\text { grade }\end{array}$ & 83.0 & 13 \\
\hline Present study & & $\geq 65$ & 90 & $\begin{array}{l}\text { Wide }(65.5 \%) \text {, marginal }(18.9 \%) \text {, } \\
\text { intralesional }(3.3 \%)\end{array}$ & ASA-PS, grade & 77.5 & \\
\hline
\end{tabular}

ASA-PS, American society of anesthesiologists-physical status.

In the present study, it was demonstrated that the 5-year overall survival rate for elderly patients with primary malignant bone and soft tissue tumors was $77.5 \%$, which was comparable to those reported in other previous studies. As shown in Table V, Lahat et al (9) reported a 5-year disease-specific survival of $63 \%$, while Kozawa et al (12) reported that the 5 -year overall survival was $72 \%$ in elderly patients with bone and soft tissue tumors. In addition, Yoneda et al (13) conducted a retrospective analysis involving 158 elderly patients with localized soft tissue sarcoma and found that the overall 5-year survival rate was $83 \%$.

Surgical removal is the conventional treatment method for malignant bone and soft tissue tumors and surgical margins are considered to be an important factor regarding curability (20). In the present study involving elderly patients with malignant bone and soft tissue tumors, a wide margin was achieved in $65.5 \%$, a marginal margin in $18.9 \%$ and an intralesional margin in $3.3 \%$ of patients. Previous reports have also demonstrated that a surgical margin without the achievement of a wide margin was evident in $14.3-33.5 \%$ of patients (Table V). This indicates that as a result of age-associated factors, orthopedic oncologists have been obliged to select less aggressive surgery for patients with malignant bone and soft tissue tumors.

In the present study, no patients underwent amputation or disarticulation. This finding may be associated with the Japanese culture, as the majority of elderly Japanese patients and their families refuse to accept amputation, even if curability may be accomplished with amputation; most of these patients choose local radiotherapy to inhibit or control tumor growth as much as possible.

Only 4 cases received systemic chemotherapy in the present study. The European Society for Medical Oncology Guidelines (26) state that adjuvant chemotherapy may improve, or at least delay, distant and local recurrence in high-risk patients. For elderly patients with high-grade bone tumors, the use of chemotherapy is disputed. Adriamycin and ifosfamide remain candidate chemotherapy drugs for treating soft tissue tumors (27). Elderly patients have been reported to suffer reduced cardiac function and renal dysfunction in response to chemotherapy $(28,29)$. Therefore, it is thought that the use of systemic chemotherapy should be limited to elderly patients free of any health problems, due to reduced physiologic function.

The results of the present study indicated that an ASA-PS score of $\geq 3$ as well as the presence of a high-grade tumor were significant predictive factors for poor prognosis. Tumor grade has previously been accepted as being a predictive factor affecting patient survival (Table V). As a novel finding in the present study, ASA-PS proved to be a factor that may be used to predict poor prognosis when evaluated using univariate and multivariate analysis. Hosking et al (19) reported that, when used as a preoperative evaluation system for the general condition of elderly patients, the ASA-PS score was associated with a poorer patient survival rate (19). In the present study, Kaplan-Meier analysis also revealed a significant difference in patient survival between those with ASA-PS scores of $\geq 3$ and 1-2. It was therefore suggested that if the preoperative condition of the patient is classified as an ASA-PS score 1 or 2, surgeons should aim to resect of as much the tumor as possible, so that the margin is as negative as possible. The concept of tumor removal may be similar to that in young patients. If the ASA-PS score is $\geq 3$, the general condition of the patient and limb function following tumor removal should be given priority and a less aggressive treatment should be selected; radiotherapy is one potential therapeutic option for the control of malignant tumors in these patients.

The results of the present study confirmed that there was no statistically significant difference in the 5-year survival rate between patients' aged $65-74$ years and those aged $\geq 75$ years. Previously, the Surveillance Epidemiology and End Results 
registries (7) demonstrated that older age was associated with poor prognostic factors. Aging is associated with decreased physiological functions and an increased prevalence of comorbidities (30); these factors may influence the management and outcome of treatment. In Japan, life expectancy for individuals aged 65 years is now 18.9 years for men and 23.9 years for women (1); these values are markedly increased compared to those reported a decade earlier (1). These finding suggested that orthopedic oncologists should reserve surgery exclusively for younger patients.

The present study had several limitations; these limitations include a small number of patients enrolled and that it was a retrospective study performed in a single Japanese institution. In addition, the follow-up period was relatively short for a complete analysis of patient survival. Furthermore, no specific guidelines have been established with regard to surgery, chemotherapy and radiotherapy; thus, treatment plans were determined by several orthopedic oncologists.

In conclusion, the number of elderly patients is continuously increasing in Japan; accordingly, the incidence of primary bone and soft tissue tumors has also been increasing. The present study demonstrated as a novel finding that preoperative risk assessment using the ASA-PS score as well as high tumor grade were significant predictive factors of poor prognosis, whereas older age was not a significant predictive factor. Thus, orthopedic oncologists should not determine the aggressiveness of tumor surgery based only on age.

\section{References}

1. Ministry of Health, Labor and Welfare of Japan: 2014 Statistics. Elderly people, natality, life expectancy. http://www.mhlw. go.jp/toukei/saikin/hw/jinkou/geppo/nengai14/index.html. Accessed 30 April, 2014.

2. World Health Organization: Health statistics and information systems definition of an older or elderly person. http://www.who. int/healthinfo/en/. Accessed 30 April, 2014.

3. Office for Policies on Cohesive Society: Cabinet Office, Government of Japan. http://www8.cao.go.jp/souki/index-eng. html. Accessed 30: April, 2014.

4. Japanese Orthopedic Association Musculoskeletal Tumor Committee. Bone Tumor Registry and Malignant Soft Tissue Tumor Registry in Japan. Japanese Musculoskeletal Oncology Group, Tokyo, 2008.

5. Anisimov VN: The relationship between aging and carcinogenesis: A critical appraisal. Crit Rev Oncol Hematol 45: 277-304, 2003.

6. Balducci L and Erchler WB: Cancer and aging: A nexus at several levels. Nat Rev Cancer 5: 655-662, 2005.

7. Al-Refaie WB, Habermann EB, Dudeja V, Vickers SM, Tuttle TM, Jensen EH and Virnig BA: Extremity soft tissue sarcoma care in the elderly: Insights into the generalizability of NCI Cancer Trials. Ann Surg Oncol 17: 1732-1738, 2010.

8. Osaka S, Sugita H, Osaka E, Yoshida Y and Ryu J: Surgical management of malignant soft tissue tumours in patients aged 65 years or older. J Orthop Surg (Hong Kong) 11: 28-33, 2003.

9. Lahat G, Dhuka AR, Lahat S, Lazar AJ, Lewis VO, Lin PP, Feig B, Cormier JN, Hunt KK, Pisters PW, et al: Complete soft tissue sarcoma resection is a viable treatment option for select elderly patients. Ann Surg Oncol 16: 2579-2586, 2009.

10. Boden RA, Clark MA, Neuhaus SJ, A'hern JR, Thomas JM and Hayes AJ: Surgical management of soft tissue sarcoma in patients over 80 years. Eur J Surg Oncol 32: 1154-1158, 2006.
11. Torigoe T, Terakado A, Suehara Y, Kurosawa H, Yazawa Y and Takagi T: Bone versus soft-tissue sarcomas in the elderly. J Orthop Surg 18: 58-62, 2010.

12. Kozawa E, Sugiura H, Tsukushi S, et al: Multiple primary malignancies in elderly patients with high-grade soft tissue sarcoma. Int J Clin Oncol 19: 384-390, 2014.

13. Yoneda Y, Kunisada T, Naka N, Nishida Y, Kawai A, Morii T, Takeda K, Hasei J, Yamakawa Y and Ozaki T; Japanese Musculoskeletal Oncology Group: Favorable outcome after complete resection in elderly soft tissue sarcoma patients: Japanese Musculoskeletal Oncology Group study. Eur J Surg Oncol 40: 49-54, 2014.

14. Flecher C, Unni K and Mertens F: Pathology and genetics of tumours of soft tissue and bone. In: World Health Organization Classification of Tumours. Kleihues P and Sobin, LH (eds). International Agency for Research on Cancer Press, Lyon, pp10-18, 2002.

15. Broders AC: Squamous cell epithelioma of the lip. A study of 537 cases. JAMA 74: 656-664, 1920.

16. Trojani M, Contesso G, Coindre JM, Rouesse J, Bui NB, de Mascarel A, Goussot JF, David M, Bonichon F and Lagarde C: Soft-tissue sarcomas of adults; study of pathological prognostic variables and definition of a histopathological grading system. Int J Cancer 33: 37-42, 1984.

17. Edge SB, Byrd DR, Compton CC, et al (eds): American Joint Committee on Cancer (AJCC): Soft tissue sarcoma. In: AJCC cancer staging manual. 7th ed. Springer, New York, NY, pp291-296, 2010.

18. Edge SB, Byrd DR, Compton CC, et al (eds): AJCC bone. In: AJCC cancer staging manual. 7th ed. Springer, New York, NY, pp281-290, 2010.

19. Hosking MP, Warner MA, Lobdell CM, Offord KP and Melton LJ III: Outcomes of surgery in patients 90 years of age and older. JAMA 261: 1909-1915, 1989.

20. Kawaguchi N, Ahmed AR, Matsumoto S, Manabe J and Matsushita Y: The concept of curative margin in surgery for bone and soft tissue sarcoma. Clin Orthop Relat Res 419: 165-172, 2004.

21. Kaplan EL and Meier P: Nonparametric estimation from incomplete observation. J Am Stat Assoc 53: 448-457, 1958.

22. Mantel N: Evaluation of survival data and two new rank order statistics arising in its consideration. Cancer Chemother Rep 50: 163-170, 1966.

23. Cox DR: Regression models and life-tables. J R Stat Soc 34: $187-220,1972$

24. Takano S, Watanabe Y, Ohishi H, Kono S, Nakamura M, Kubota N and Iwai S: Multimodality treatment for patients with hepatocellular carcinoma: A single institution retrospective series. Eur J Surg Oncol 26: 67-72, 2000.

25. Suemitsu R, Yamaguchi M, Takeo S, Ondo K, Ueda $H$, Yoshino I and Maehara Y: Favorable surgical results for patients with nonsmall cell lung cancer over 80 years old: A multicenter survey. Ann Thorac Cardiovasc Surg 14: 154-160, 2008.

26. ESMO/European Sarcoma, Network Working Group: Soft tissue, visceral sarcomas: ESMO clinical practice guidelines for diagnosis, treatment and follow-up. Ann Oncol 23 (Suppl 7): vii92-vii99, 2012.

27. Linch M, Miah AB, Thway K, Judson IR and Benson C: Systemic treatment of soft-tissue sarcoma-gold standard and novel therapies. Nat Rev Clin Oncol 11: 187-202, 2014.

28. Farry JK, Flombaum CD and Latcha S: Long term renal toxicity of ifosfamide in adult patients - 5 year data. Eur J Cancer 48: 1326-1331, 2012

29. Matushansky I, Dela Cruz F, Insel BJ, Hershman DL and Neugut AI: Chemotherapy use in elderly patients with soft tissue sarcoma: A population-based study. Cancer Invest 31: 83-91, 2013.

30. Vigorito C and Giallauria F: Effects of exercise on cardiovascular performance in the elderly. Front Physiol 5: 51, 2014. 